\title{
IDENTIFICACIÓN ESPACIALMENTE EXPLÍCITA DE LAS ZONAS DE PROBLEMÁTICAS Y DE APTITUD PARA EL DESARROLLO DEL TURISMO DE BASE COMUNITARIA EN LA COMUNA DE PANGUIPULLI - SUR DE CHILE
}

\author{
Amelia Miranda Fica \\ Administradora de Empresas de Turismo dela Universidad Austral de Chile \\ Magíster Manejo de Recursos Naturales de la Universidad de la Frontera, Chile.

\section{Guillermo Pacheco Habert} \\ Administrador de Empresas de Turismo de la Universidad Austral de Chile, \\ Magíster en Ciencias Sociales, CEDER Universidad de Los Lagos, Chile. \\ Doctorando en Ciencias Sociales en Estudios Territoriales, \\ Universidad de Los Lagos. Investigador \\ NIAP - CEAM UACh.

\section{Raul Orrego Verdugo} \\ Ingeniero en Recursos Naturales, Universidad de Chile. \\ Doctor en Recursos Naturales, Universidad de la Frontera.
}

\section{Resumen}

Se realizó una investigación de carácter exploratoria que recopila información primaria y secundaria, capas de información geográfica, aplicación de softwares Idrisi y ArcGis, que permitan realizar un Análisis estadístico y de datos geográficos de Multicriterios aplicados al Turismo de Base Comunitaria (TBC), en la comuna de Panguipulli, XIV Región de Los Ríos - Chile, para de ésta forma exhibir explícitamente las problemáticas que afectan la implementación de este tipo de turismo en diferes áreas. Se generaron mapas temáticosque exponen las limitantes de caráctereconómico, organizacionaly faltadeinfraestructura en base al levantamiento de encuestas realizadas a tres tipos de actores que intervienen en su implementación, comunidad local, panel de expertos y gestores gubernamentales, quienesaplicaronpesossegúnsuspercepcionesalas problemáticamediantelamatrizdeSaaty.

Palabras clave: TBC, Análisis Multicriterio, Matriz de Saaty. 


\title{
SPATIALLY EXPLICIT METOD FOR IDENTIFICATION OF AREAS OF PROBLEMS AND APTITUDES FOR THE DEVELO- PMENT OF COMMUNITY BASED TOURISM IN THE PANGUI- PULLI COMMUNE, SOUTHERN CHILE
}

\author{
Amelia Miranda Fica \\ Administradora de Empresas de Turismo dela Universidad Austral de Chile, \\ Magister Manejo de Recursos Naturales de la Universidad de la Frontera.

\section{Guillermo Pacheco Habert} \\ Administrador de Empresas de Turismo de la Universidad Austral de Chile, \\ Magíster en Ciencias Sociales, CEDER Universidad de Los Lagos, \\ Doctorando en Ciencias Sociales en Estudios Territoriales, \\ Universidad de Los Lagos, Chile. Investigador \\ NIAP - CEAM UACh.

\section{Raul Orrego Verdugo} \\ Ingeniero en Recursos Naturales, Universidad de Chile. \\ Doctor en Recursos Naturales, Universidad de la Frontera.
}

\begin{abstract}
An exploratory research was done that collects primary and secondary information, layers of geographic information, application of Idrisi and ArcGis softwares, that allow to perform a statistical analysis and geographical data of Multicriteria applied to Community Based Tourism (CBT), in the Panguipulli comune, "Region de Los Ríos - Chile", in order to exhibit explicitly the problems that affect the implementation of this type of tourism in different areas. Some thematic maps were generated that expose the limitations of economic and organizational factors and lack of infrastructure, based on the surveys applied to three types of actors involved in its implementation, the local community, panel of experts and government managers, who applied relative weights according to their perceptions to the problematics through Saaty's matrix.
\end{abstract}

Keyword: CBT, Multicriteria Analysis, Saaty's matrix. 
El Turismo de Base Comunitaria (TBC) tiene la particularidad de atenuar los impactos negativos producido por el turismo masivo puesto que se enfoca en tres conceptos claves a) comunidad b) convivenciabilidad y c) cotidianidad los cuales presentan una alta tendencia social y humana puesto que su enfoque de desarrollo está en fomentar la organización, la cohesión colectiva de las comunidades que lo ejecutan y puesta en valor de las tradiciones locales que existen en las localidades particulares donde se adopta, desvinculándose de la filosofía neoliberal que promueve el turismo tradicional y masivo. .

Debido a lo anterior es que este tipo de turismo es considerado por algunos autores como una alternativa de generación de recursos locales paralela al sistema económico neoliberal predominante a nivel mundial que visibiliza estilos de vida tradicionales existentes en territorios de características rurales, promoviendo a la vez la gestión integrada y participativa en los recursos económicos generados por las comunidades locales, el enriquecimiento de las interacciones sociales y la valorización y cuidado participativo de los recursos naturales.

El turismo como toda actividad productiva necesita de bases de datos de información cualitativa, cuantitativa y geográfica amplia, consistente y especifica que involucre funciones dinámicas, modificables, adaptables y eficientes de los mismos que permita los respectivos análisis estadísticos y geográficos espaciales.

El análisis espacial del territorio que corresponde a una técnica que proporciona bases de datos de información geográfica relevante debido a la combinación de datos cualitativos, cuantitativos y territoriales aplicados para diferentes áreas de investigación donde se involucren actividades productivas, de construcción, de ordenamiento territorial en el territorio facilitando a los actores la toma de decisiones para la planificación estratégica que contribuya a la toma de decisiones de ordenamiento y planificación territorial para aportar a la eficiente adaptación de políticas públicas y privadas que fomenten diversas actividades desarrolladas por el hombre tales como agricultura, actividades forestales, ganadería, construcción de viviendas, de industrias, de caminos, turismo y delimitación de terrenos para la protección humedales o espacios territoriales de alto valor en su biodiversidad provocados por su riqueza ecosistemica y características climatológicas.

Se realizó una investigación de carácter exploratoria que recopila información primaria y secundaria, datos geográficos, capas de información geográfica, aplicación de softwares Idrisi y ArcGis, que permitan realizar un análisis estadístico y de datos geográficos de Multicriterios aplicado al TBC, en la comuna de Panguipulli, Región de Los Ríos - Chile, para de ésta forma exhibir explícitamente las problemáticas que afectan la implementación de este tipo de turismo en diferentes áreas, siendo posible generar mapas temáticos que exponen las limitantes de carácter económico, organizacional y falta de infraestructura en 
base al levantamiento de encuestas realizadas a tres tipos de actores que intervienen en su implementación, comunidad local, panel de expertos y gestores gubernamentales, quienes aplicaron pesos según sus percepciones a las problemática mediante la matriz de Saaty. Los mapas están compuestos por capas de datos geográficos que otorgan información compilada en el área seleccionada para el diagnóstico y análisis de multicriterios de las variables seleccionadas que intervienen en su ejecución y delimitación de zonas de aptitud del Turismo de Base Comunitaria. Los mapas temáticos representan una herramienta de ordenamiento territorial concreto para investigadores, comunidad local y organismos públicos o privados que facilitan los procesos de toma de decisiones para establecer estrategias, acciones y programas de desarrollo territorial que contribuyan al desarrollo del Turismo de Base Comunitaria de la comuna de Panguipulli.

\section{Marco Teórico}

La actividad económica generada por la industria turística, según estudios realizados por la Asociación internacional Wold Travel and Tourism Coursil, aportó al Producto Interno Bruto (PIB) a nivel mundial durante el año $2016 \$ 2.400 .000 .000$, lo que correspondiente a un $9.8 \%$ del total de las industrias que conforman este índice. Asimismo como industria presentó un crecimiento anual de un $3.7 \%$, experimentando un incremento de un $0.3 \%$ más que el PIB económico global, es por esto que se proyecta un crecimiento económico de la actividad de un 4\% hacia el año 2020. En cuanto a los puestos laborales creados por la industria turística se clasifican en directos, indirectos e inducidos, los que alcanzan un total de 290.000.000 plazas, lo que representa un $9,4 \%$ del total de la taza de empleo cuantificada a nivel mundial.

Mencionar que el Producto Interno Bruto (PIB) está compuesto por los recursos monetarios generados por la producción interna de productos y servicios de los diferentes sectores productivos que existen en un país en donde la variación anual del índice que lo mide sea esta negativa o positiva determina el crecimiento o declinación económica en un país. Lo anterior se explica para profundizar en cómo se determina el aporte de la actividad turística en el Producto Interno Bruto de un país, composición que considera como base la producción valorizada según los ingresos monetarios que genera la actividad turística en cada uno de sectores productivos de un país como la agricultura, ganadería, construcción, comercio de servicios básicos, transportes y comunicaciones complementados con los ingresos brutos generados sólo por los servicios que forman parte de la industria turística, los que en la mayoría de los países son emanados por la hotelería y la restauración. A esta clasificación de aporte al Producto Interno Bruto se le denominada, Valor agregado Bruto (VAP) (Brida, et.al, 2008). 
Asociado a los conceptos de medición que involucra la industria turística, es posible sostener que esta se ajusta debido a sus manifestaciones a la economía de libre mercado, puesto que su crecimiento está medido a nivel mundial en el índice porcentual de aporte al PIB, de la misma forma que el mercado exige maximizar las rentabilidades en la empresas turísticas propiciando así la acumulación capital económico en periodos de tiempo establecidos, los resultados de los estados contables determinan su posicionamiento en la industria a nivel local, nacional o internacional según donde se desenvuelva cada empresa que fructifica de la actividad. Así también existe un elemento básico que los encuadra en el sistema de libre mercado, como es la determinación de precio de los servicios turísticos, compuesto por las fuerzas invisibles emitidas desde la oferta y la demanda como según la elasticidad de una de estas fuerzas, se adapta buscando el punto de equilibrio en los ejes del plano cartesiano que lo exhibe según los principios que rigen aún a la economía.

Desde el punto de vista de la influencia que ejerce el turismo en los acreedores, las cadenas de producción, la necesaria creación de fuentes laborales y crecimiento del número de empresas turísticas es posible aportar a la tazas de empleos en porcentajes que bordea el $10 \%$ en las ciudades y países donde se desarrolla. Sin embargo existe cantidades considerables de casos donde la actividad no considera ni cuantifica los impactos negativos que provoca en los ámbitos sociales, económicos y ambientales tales como la especulación inmobiliaria, la marginación de las poblaciones más vulnerables en áreas periféricas de los centros urbanos, alza de precios para la población local, intervención culturas tradicionales, impactos ambiental por sobrepasar la capacidad de carga de las centros urbanos y rurales donde se desarrolla la actividad deteriorando los recursos naturales en toda su expresión lo que involucra baja en cantidades de especies de fauna y flora por la extracción de especies exóticas y endémicas a favor de su crecimiento.

Para Santillan 2010, la actividad ejecutada de manera tradicional y de forma masiva es considerada un corredor de la globalización y facilitador de la expansión el del actual sistema neoliberal que fomenta el progreso económico-social y la modernización de los espacios donde este se desarrolla sean estos espacios clasificados como áreas urbanas o rurales.

Como respuesta a las debilidades que existe en la implementación del turismo masivo emerge el Turismo de Base Comunitaria. Un tipo de turismo que favorece la cohesión de los lazos sociales y un sentido colectivo de realizar vida en sociedad promoviendo la calidad de vida, el sentido de inclusión social, la valorización de la cultura local y el sentido de pertinencia (Bartholo, et.al 2009). Es posible decir entonces que este tipo de turismo representa una interpretación "local" del turismo frente a la demanda turística que busca contextos de grupos sociales diferentes o específicos en un destino que considera al final de cuentas, un escenario de fondo la dinámica de un mundo globalizado e integrado al sistema económico predominante. 
El desarrollo histórico del Turismo de Base Comunitaria ha tenido un crecimiento importante en América Latina, su nacimiento que se genera a mediados de los años 80 del siglo XX, como resultado de las presiones del mercado turístico, demanda con tendencias a practicar turismo cultural y de naturaleza, que se fundamenta en cuatro perspectivas a satisfacer; nacientes mercados de turismo de intereses especiales que buscan vivir experiencias originales en paisajes naturales y culturales, disminuir los altos índices de pobreza e indigencia que los afectan a poblaciones de América del Sur tanto de áreas urbanas y rurales, una actividad productiva que puede renovar la economía local, crear nuevas fuentes de ingresos económicos en áreas rurales y una herramienta de resistencia política territorial para las poblaciones indígenas ya que promueve la propiedad de terrenos ancestrales, la preservación del patrimonio cultural y los recursos naturales (Bartholo, et.al 2009). Para complementar Sampaio, et al 2007 y Coroliano, 2006, consideran que el Turismo de Base Comunitaria es una alternativa de desarrollo económico local, complementario y justo con las comunidades que lo adoptan porque agrega valor a las costumbres y tradiciones intrínsecas de las comunidades dado que reduce los impactos negativos que provoca el turismo masivo. Otros autores suscitan que es una estrategia de comunicación social que promueve la conservación de modos de vida de comunidades tradicionales y la gestión integrada y a la vez participativa de los recursos naturales (Hernriquez, 2013).

Sin embargo, la implementación y ejecución del Turismo de Base Comunitaria (TBC) es compleja a causa de su alta sensibilidad a las percepciones sociales de quienes actúan en su ejecución porque incorpora a un rubro económico altamente competitivo y globalizado sumado a aquello, el TBC es adoptado en su gran mayoría por comunidades tradicionales, reducidas y con patrones sociales específicos tanto rurales como urbanos con poca experiencia en generar recursos económicos alternativos fuera de los tradicionales (Bartholo, et.al 2009). Lo que a su vez posee muchas limitantes que dilucidan estudios aplicados, éstas son: a) bajos índices de formalización de los emprendimientos; b) falta de certificación pertinente con la identidad; c) presencia de conflictos productivos; d) falta de escenarios y estrategias de asociatividad; e) falta de promoción y difusión; f) poca experiencia en la administración de recursos económicos y humanos g) poca participación de las comunidades locales en los procesos de planificación política y territorial; h) falta de capacitaciones especializadas en el área; i) estacionalidad propia de la demanda turística; j) pocas posibilidades de co-gestión integrada con áreas protegidas y k) bajo interés en el rescate y preservación del patrimonio cultural (Pacheco, 2015). 
El diagrama 1. Sintetiza las limitantes percibidas por la comunidad local de la comuna de Pangupulli para la ejecución del Turismo de Base Comunitaria a fin de ordenar las problemáticas mencionadas anteriormente.

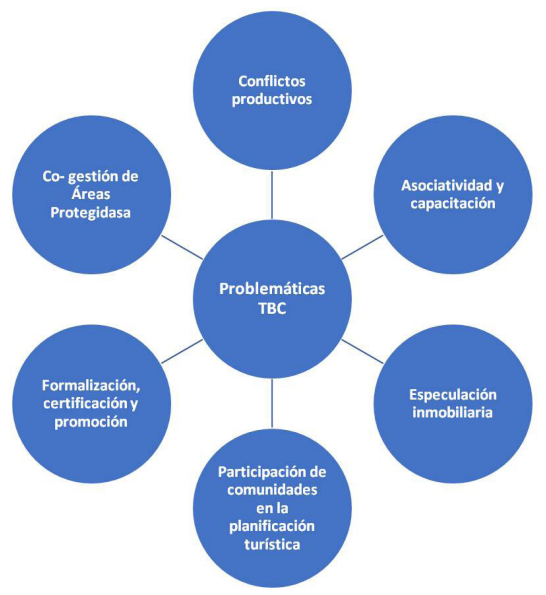

Muchas de las problemáticas expuestas tienen una fuerte dimensión espacial por tanto para visualizarlas es necesario investigar sobre los datos geográficos que permitan aplicar, agrupar las percepciones de los actores que intervienen en su implementación sean estos los actores públicos, privados, locales y nacionales y procesar las inquietudes. Este es un desafío que se puede solucionar asociando dos disciplinas la gestión turística y el análisis espacial.

La gestión turística se refiere a la capacidad de dirigir destinos, organismos y empresas turísticas a través del diseño de estrategias, procesos, optimización de recursos y cumplimiento de objetivos para contribuir al desarrollo y competitividad de la industria turística, en tanto que el Análisis espacial una técnica que permiten analizar las variables de un problema en el espacio, descubrir cómo estas variables se interrelacionan y afectan a ciertos procesos de un territorio determinado.

El análisis espacial en específico se define como un proceso que selecciona datos geográficos de un área e incluye funciones de superposición tipológica, generación de corredores o modelación de datos con el fin de descubrir estructuras espaciales, asociaciones y relaciones entre las variables geográficas, las que son posibles estudiarlas a través de la incorporación de modelos espaciales, la cual se describe como la representación de atributos de la superficie terrestre en una base de datos digital que apunta a la solución de un problema complejo (González, 2012). 
El uso de métodos de modelación espacial, ofrece bases de datos dinámicos y espaciales, los cuales se utilizan para configurar un sistema de tecnología informática que aporte a la investigación geográfica y al proceso de toma de decisiones para la solución de problemas territoriales complejos, debido a la gestión eficiente de los datos que conlleva el proceso, esta favorece el análisis espacial, multi-factor y capacidades de monitoreo constante. Este proceso entonces se convierte en una herramienta que facilita la toma de decisiones eficaces y ayuda a la gestión de la tierra, la planificación urbana, la prevención y mitigación de desastres, el desarrollo inmobiliario, comercial y otras áreas que así lo requiera (Wei Wei, 2012).

Para realizar análisis espaciales, los Sistemas de información Geográfica son fundamentales, estos sistemas se describe como un conjunto de partes en interacción organizadas que permite manejar datos geográficos, es una disciplina emergente que reúne geografía, ciencias de la computación, matemáticas, estadística, gestión, topografía y cartografía en una sola, sobre la base de los datos geoespaciales, los que apoyados por hardware y software, se recoge datos de entrada, los cuales se gestionan, editan, modelan y visualizan la información geográfica (Wei Wei, 2012).

Los Sistemas de Información Geográfica se han incorporado al análisis del fenómeno turístico como herramientas de planificación para los destinos turísticos y sistemas de apoyo al proceso de toma de decisiones, proporcionado la construcción de completas bases de datos de geografía turística, mapas temáticos y sistemas de información comprimida y complementaria a las actuales bases de información, que existe ligada la actividad turística.

Las bases de datos y fuentes de información actual que existe sobre el rubro turístico son deficientes y poca en cantidad, esta situación dificulta la toma de decisiones y la operación y la proyección de esta actividad económica en las naciones, la mayoría de las investigaciones e información tiende a realizarse desde una lógica tradicional y de absolutos en análisis de parámetros estadísticos y no consideran la evolución y tendencias del mercado turístico actual. El TBC en especial exige ser tratado con una visión amplia y sólida con respecto a los procesos humanos y sociales que involucra, por lo que generar información y bases de datos de una lógica absoluta desde lo cualitativo, cuantitativo o estadístico aporta poco a su entendimiento y evolución geografica.

El TBC es un problema de investigación complejo, que necesita ser tratado desde una perspectiva transdiciplinaria y multidisciplinaria debido a los multiples factores que intervienen en su ejecución. Además, es un tipo de turismo muy sensible a las decisiones de los actores que intervienen en su desarrollo por lo tanto, para investigar su situación actual se debe considerar esta característica. 
Para realizar análisis espacial de múltiples factores aplicado al TBC, es necesario utilizar metodologías que se adapten a los requerimientos de su tratamiento, entonces el presente estudio utiliza la metodología de Análisis de Evaluación de Multicriterio, herramienta que mediante un conjunto ordenado y sistemático de etapas permite integrar múltiples criterios para aportar a la solución de un problema complejo. La metodología involucra, la elección de diferentes capas de datos geográficos que apuntan a un solo propósito, los cuales seleccionados, procesados y editados permiten crear mapas temáticos para diferentes propósitos, tales como conservación de terrenos forestales, uso de suelos agrícolas, protección de áreas de la expansión urbana, zonas de aptitud turística u otros. Los mapas generados asisten eficientemente al ordenamiento y planificación territorial y al manejo de los recursos naturales (Lopez et. al, 2011).

En esta investigación se realizará un análisis de Evaluación Multicriterio de problemáticas presentes que debilitan el TBC en destino Siete Lagos (comuna de Panguipulli) con el objetivo de asistir al proceso de toma de decisiones y la planificación territorial turística a investigadores, gestores y comunidad local; Contribuyendo así, a la eficacia de las estrategias para el fomento del TBC y a la economía solidaria, a la inyección y distribución focalizada de recursos públicos o privados y direccionar políticas y programas públicos que aporten al desarrollo económico local del Turismo de comunidades locales en zona rurales de la comuna de Panguipulli.

\section{Objetivo General}

Realizar un análisis espacial de las problemáticas que limitan el desarrollo del Turismo de Base Comunitaria en el destino Siete Lagos de la comuna de Panguipulli, Región de los Ríos.

\section{Objetivos específicos}

1- Definir criterios para la evaluación de las problemáticas del Turismo de Base Comunitaria.

2- Ponderar estos criterios para desarrollar un modelo espacial de evaluación de las problemáticas.

3- Crear mapas temáticos de las problemáticas del TBC, que asista al análisis territorial de TBC en la comuna de Panguipulli.

4- Crear mapas temáticos de aptitud del TBC, que asista a la planificación y toma de decisiones en la comuna de Panguipulli. 


\section{Metodología}

Formulación del Análisis multicriterio.

Esta investigación, se basó en la metodología denominada Análisis Multicriterio, que consiste en un conjunto ordenado y sistemático de etapas que permite integrar múltiples criterios en el análisis de los cambios espaciales de un territorio. Es usada frecuentemente en procesos de planificación territorial y en la conservación de los recursos naturales (Lopez-Marreno, et. al 2011).

El análisis multicriterio será aplicado, en la gestión del Turismo de Base Comunitaria que se desarrolla en la comuna de Panguipulli, donde intervienen múltiples aspectos que limitan el crecimiento de este tipo de turismo. A estos aspectos los denominaremos criterios o problemáticas del TBC. En este trabajo fueron considerados las siguientes:

a) Problemática de Conflictos Productivos: Se definen como aquellas actividades productivas que compiten en el uso de territorio con el TBC. En particular, en la zona se identificaron tres de estos conflictos: Proyectos Hidroeléctricos; Zonas de Turismo Masivo y Zonas de Especulación Inmobiliaria. Estos conflictos de uso, fueron denominados sub criterios de conflictos productivos.

b) Problemática de Gestión Comunitaria: Se definen como aquellas condiciones, cuya ausencia dificulta la gestión territorial local comunitaria para la ejecución del TBC. En este caso son: que la zona pertenezca a una Área Protegida, Ausencia de Organizaciones Comunitarias y Ausencia de Terrenos Indígenas. Estas condiciones fueron denominadas, sub criterios de Gestión Comunitaria.

c) Problemática insuficiencia de Infraestructura Turística: Se definen como aquellas instalaciones que al no existir dificultan el desarrollo de la actividad turística en el área de estudio y en particular la realización de TBC, tres de estos aspectos son; la No existencia de Caminos, la No existencia de Atractivos Turísticos y la No existencia de Empresas Turísticas formalizadas. Estas problemáticas fueron denominadas, sub criterios de Infraestructura Turística.

Una vez, establecido los aspectos que representan las problemáticas para el Turismo de Base Comunitaria, es necesario cuantificarlos. Como cada criterio está compuesto por sub criterios, se establecieron variables numéricas, para evaluar el impacto de cada uno de ellos en el territorio. Todas estas variables fueron trabajadas a partir de archivos espacialmente explícitos, los que fueron trabajados en el software IDRISI, versión Selva. A continuación se presenta el detalle de las variables definidas para cada sub criterio. 


\section{a) Problemática de Conflictos Productivos.}

Proyectos hidroeléctricos: Esta variable tiene un comportamiento que varía de manera lineal decreciente con respecto a la distancia a los proyectos hidroeléctricos, tanto en ejecución como proyectados. Este decrecimiento llega hasta un valor mínimo de impacto de la problemática, dicho valor mínimo se definió en base a la estimación de un panel de expertos (ver Acápite II), que evalúo en cuanto disminuye el valor de un sector para el Turismo de Base Comunitaria por el hecho de estar cerca de una central hidroeléctrica (Figura 1). Cabe señalar que la ubicación de los proyectos hidroeléctricos, se obtuvo preguntando directamente al panel de expertos y revisión de noticias y documentos relacionados con la zona de estudio.

Figura 1. Comportamiento de problemática para los Proyectos Hidroeléctricos.

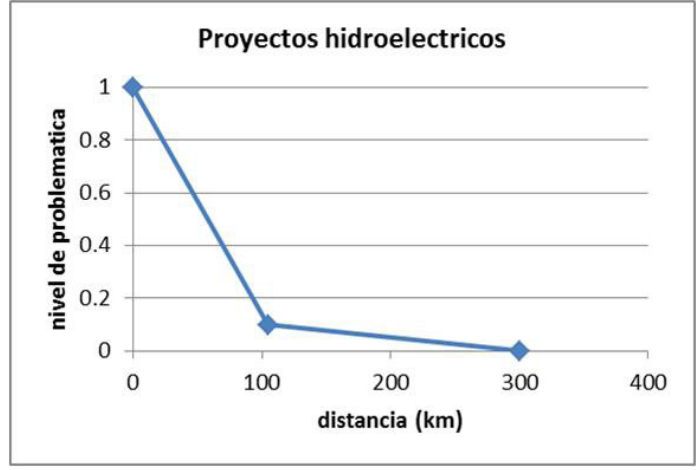

Zonas de Turismo Masivo: Esta variable tiene un comportamiento que varía de manera lineal decreciente con respecto a la distancia a las riveras de lagos presentes en la zona. Este decrecimiento llega hasta un valor mínimo de impacto de la problemática. Dicho valor mínimo se definió en base a la estimación de un panel de expertos (ver Acápite II), que evalúo en cuanto disminuye el valor de un sector para el Turismo de Base Comunitaria por el hecho de estar cerca de una zona de Turismo Masivo (Figura 2). Cabe señalar que la ubicación de las masas de agua, se obtuvo de la base de datos de mapas vectoriales de Masas de agua: polígono de lagos, lagunas, hielos y otros, disponibles por el Sistema Integrado de Información Territorial (SIIT) de la Biblioteca de Congreso Nacional de Chile. 
Figura 2. Comportamiento de problemática para las Zonas de Turismo Masivo.

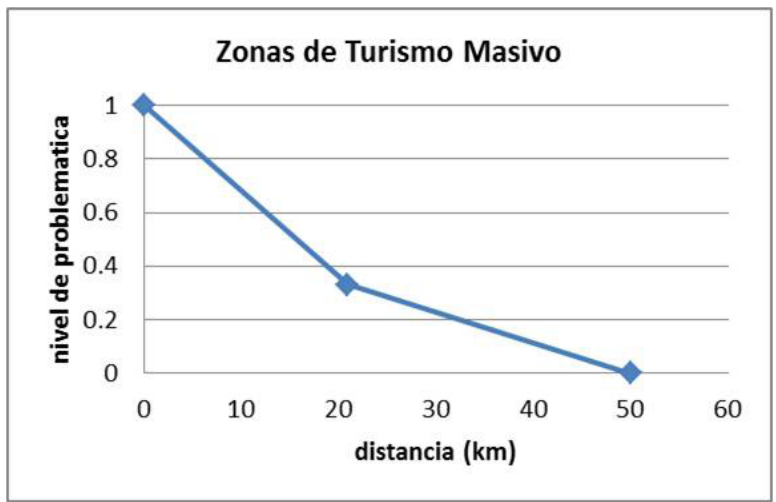

Zonas de Especulación Inmobiliaria: Esta variable tiene un comportamiento que varía de manera lineal decreciente con respecto a la distancia a las ciudades presentes en la zona. Este decrecimiento llega hasta un valor mínimo de impacto de la problemática. Dicho valor mínimo se definió en base a la estimación de un panel de expertos (ver Acápite II), que evalúo en cuanto disminuye el valor de un sector para el Turismo de Base Comunitaria por el hecho de estar cerca de una zona de Especulación Inmobiliaria (Figura 3). Cabe señalar que la ubicación de las ciudades, se obtuvo de la base de datos de mapas vectoriales de áreas urbanas de todo Chile, disponibles por el Sistema Integrado de Información Territorial (SIIT) de la Biblioteca de Congreso Nacional de Chile.

Figura 3. Comportamiento de problemática para las Zonas de Especulación Inmobiliaria.

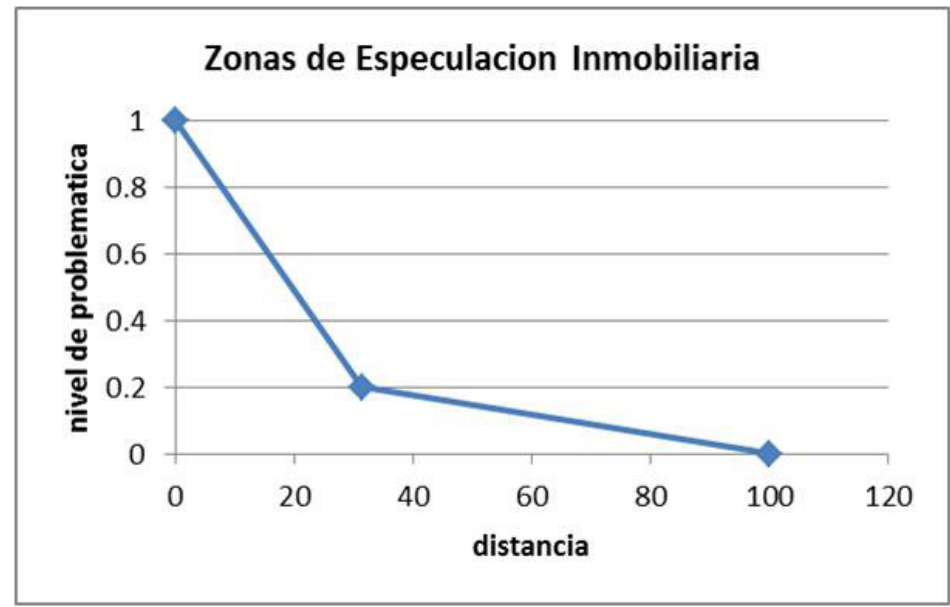


b) Problemática de Gestión Comunitaria.

Pertenencia a un Área Silvestre Protegida: Esta variable corresponde a una restricción, ya que tiene dos respuestas frente a la problemática: a) permite la gestión del TBC y b) no permite la gestión del TBC. Así, en una Área Silvestre Protegida, debido a los aspectos legales que destina estas áreas a la conservación y preservación de los terrenos no se pueden desarrollar proyectos turísticos por la comunidad local. Cabe señalar que, debido al algoritmo matemático utilizado, el valor 0 indica las zonas donde no se puede desarrollar TBC, en tanto que el valor 1 implica una dificultad máxima. De esta forma las zonas con valores cercanos a 0 , son las óptimas para el desarrollo de proyectos turísticos comunitarios.

La ubicación de las Áreas Protegida de la comuna, se obtuvo de la base de datos de mapas vectoriales de Áreas Silvestres Protegidas por el estado para todo Chile, disponibles por el Sistema Integrado de Información Territorial (SIIT) de la Biblioteca de Congreso Nacional de Chile.

Figura 4. Comportamiento de problemática para la Pertenencia a Áreas Silvestres Protegidas.

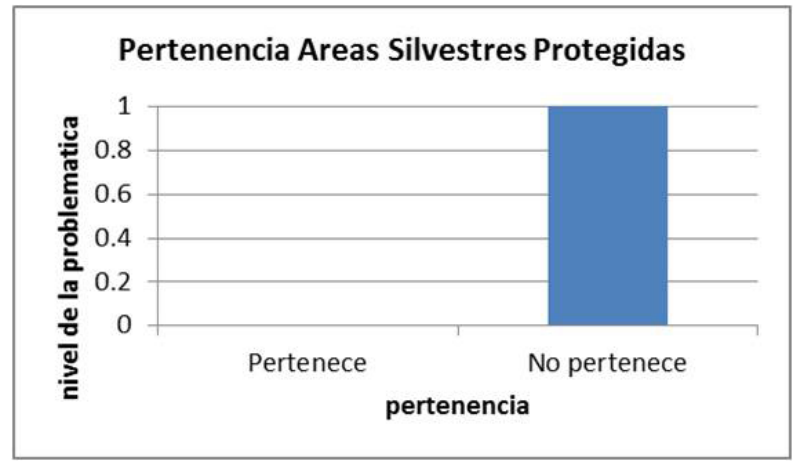

Ausencia de Organizaciones comunitarias: Esta variable tiene un comportamiento que varía de manera lineal creciente con respecto a la distancia a comunidades indígenas presentes en la zona. Este crecimiento de la problemática, llega hasta un valor mínimo de impacto de la problemática. Dicho valor mínimo se definió en base a la estimación de un panel de expertos (ver Acápite II), que evalúo en cuanto disminuye el valor de un sector para el Turismo de Base Comunitaria por el hecho de estar lejos de una Organización Comunitaria (Figura 5). Cabe señalar que la ubicación de las Comunidades Indígenas de la comuna de Panguipulli, se obtuvo de la base de datos geográficos de Comunidades Indígenas registradas formalmente y disponibles en puntos KML por el Sistema Integrado de Información Indígena de la Corporación Nacional de Desarrollo Indígena (CONADI) de la Región de Los Ríos. 
Figura 5. Comportamiento de problemática para la Ausencia de Organizaciones Comunitarias.

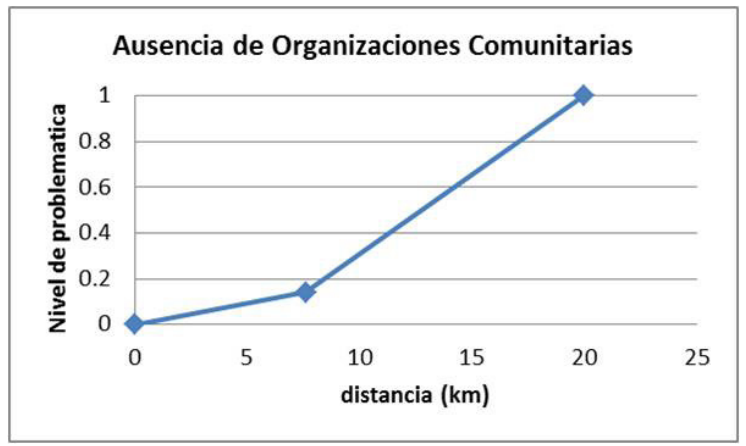

No pertenencia a Terrenos Indigenas: Esta variable tiene un comportamiento binario con respecto a si una No pertenencia a Terrenos Indígenas: Esta variable tiene un comportamiento binario con respecto a si una zona pertenece o no a un terreno indígena. Si la zona es terreno indígena tiene un valor mínimo de impacto de la problemática en tanto que si no pertenece tendrá el valor máximo. Dicho valor mínimo se definió en base a la estimación de un panel de expertos (ver Acápite II), que evalúo en cuanto disminuye el valor de un sector para el Turismo de Base Comunitaria por el hecho de no pertenecer a Terreno Indígena (Figura 6). Cabe señalar que la ubicación de los Terrenos Indígenas, se obtuvo de la base de cubiertas de polígonos de Títulos de Merced disponibles por el Sistema Integrado de Información Indígena de la Corporación Nacional de Desarrollo Indígena (CONADI) de la región de Los Ríos.

Figura 6. Comportamiento de la problemática para la No Pertenencia a Terrenos Indígenas.

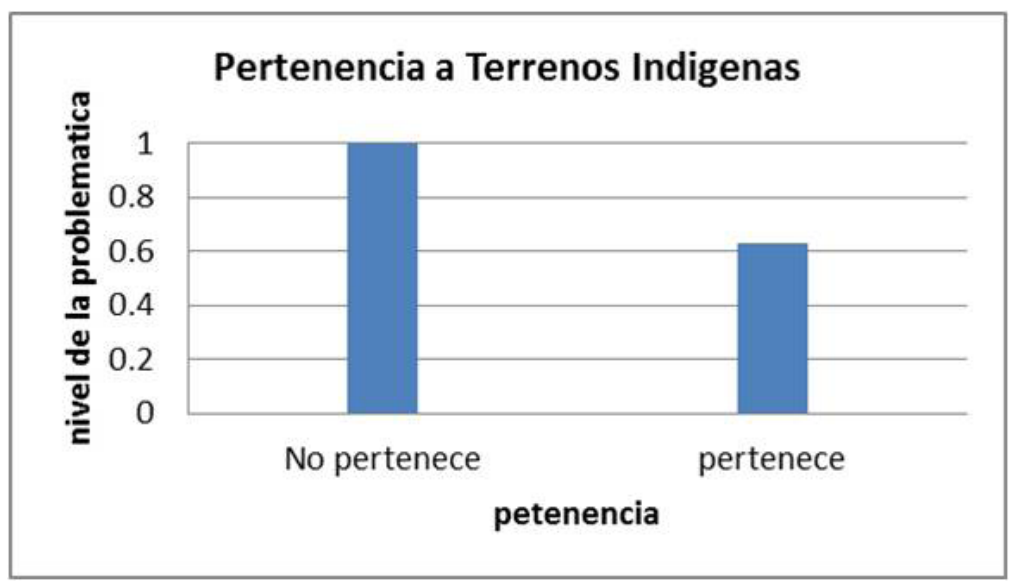


c) Problemática de insuficiencia de Infraestructura Turística.

Lejanía a caminos: Esta variable tiene un comportamiento que varía de acuerdo a valores mínimos con respectos a un tramo de distancia que contempla un punto muy cercano a caminos y otro punto muy lejano a caminos. El tramo de valores mínimo y máximo se definió en base a la estimación de un panel de expertos (ver Acápite II), que evalúo en cuanto disminuye el valor de un sector para el Turismo de Base Comunitaria por el hecho de estar muy cerca y estar muy lejos de un camino (Figura 7). Cabe señalar que la ubicación de los caminos, se obtuvo de la base de datos de mapas vectoriales de Red vial: poli líneas de los caminos de Chile, disponibles por el Sistema Integrado de Información Territorial (SIIT) de la Biblioteca de Congreso Nacional de Chile.

Figura 7. Comportamiento de problemática para Lejanía a Caminos.

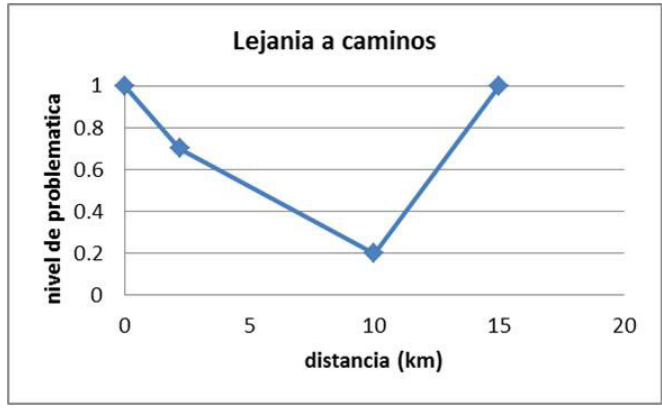

Ausencia de Atractivos Turísticos: Esta variable tiene un comportamiento que varía de manera lineal creciente con respecto a la distancia a atractivos turísticos presentes en la zona. Este crecimiento llega hasta un valor mínimo de impacto de la problemática. Dicho valor mínimo se definió en base a la estimación de un panel de expertos (ver Acápite II), que evalúo en cuanto disminuye el valor de un sector para el Turismo de Base Comunitaria por el hecho de estar lejos de un atractivo turístico (Figura 8). Cabe señalar que la ubicación de los atractivos turísticos, se obtuvo de la base de datos de mapas vectoriales de atractivos turísticos disponibles por el Sistema Integrado de Información Territorial (SIIT) de la Biblioteca de Congreso Nacional de Chile. 
Figura 8. Comportamiento de problemática para Ausencia de Atractivos Turísticos.

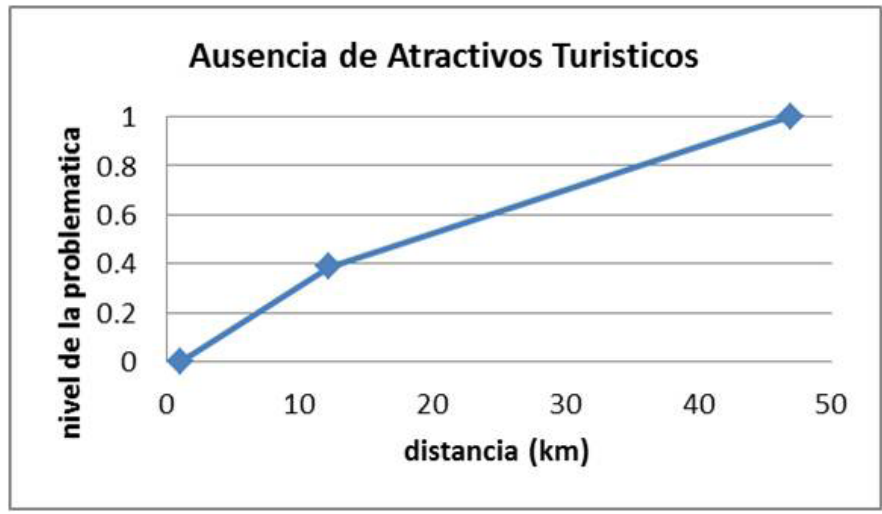

Ausencia de Empresas Formalizadas: Esta variable tiene un comportamiento constante, que es mínimo si la zona no posee empresas formalizadas. Dicho valor mínimo se definió en base a la estimación de un panel de expertos (ver Acápite II), que evalúo en cuanto disminuye el valor de un sector para el Turismo de Base Comunitaria por no tener empresas formalizadas (Figura 3). Cabe señalar que la ubicación de las empresas formalizadas, se obtuvo de la base de datos de puntos geográficos facilitados por el departamento de Turismo de la Municipalidad de Panguipulli de la región de Los Ríos.

Figura 9. Comportamiento de problemática de Ausencia de Empresas Formalizadas.

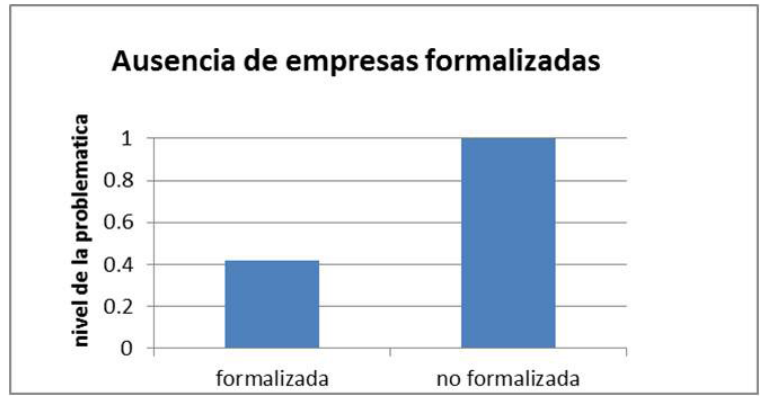

Adicionalmente, se eliminaron las cubiertas de masas de agua, por corresponder a zonas en que es imposible realizar actividades de TBC. Estas coberturas fueron obtenidas desde la base de datos de mapas vectoriales de masas de agua: polígono de lagos, lagunas, hielos y otros, disponibles por el Sistema Integrado de Información Territorial (SIIT) de la Biblioteca de Congreso Nacional de Chile. En la Figura 10, se resumen los criterios y subcriterios trabajados. 
Identificación espacialmente explícita de las zonas de problemáticas y de aptitud para el desarrollo del turismo de base comunitaria en la comuna de Panguipulli - Sur de Chile.

Gest. tur, $\mathrm{N}^{\circ} 28$, julio - diciembre 2017, pp 61 - 92.
Amelia Miranda Fica Guillermo Pacheco Habert Raul Orrego Verdugo

Figura 10: Criterios y Sub-criterios que limitan el desarrollo del Turismo de Base Comunitaria.
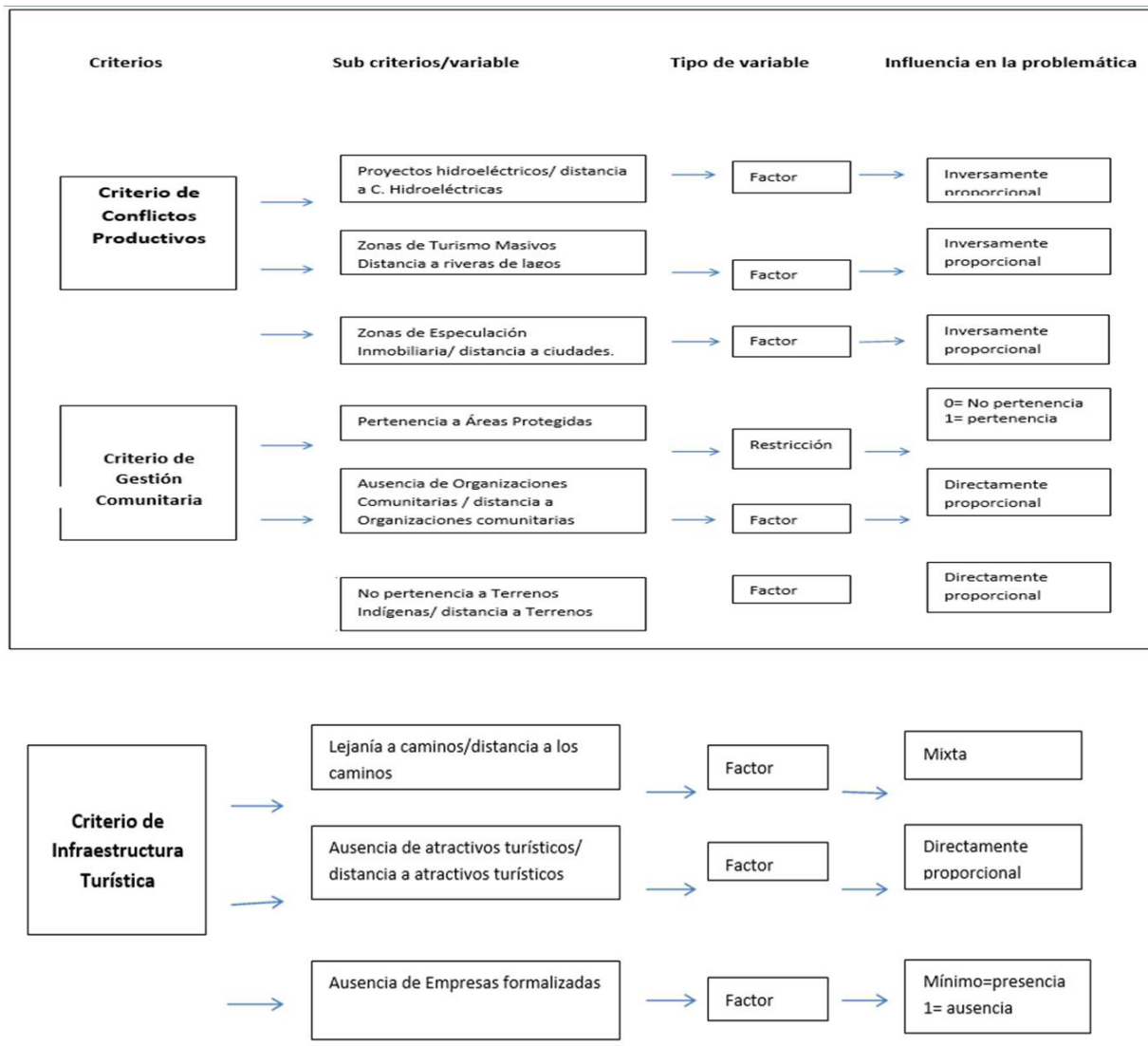


\section{Realización de encuestas}

Para determinar valores mínimos de impacto de las problemáticas, los kilómetros de influencia de la problemática y asignar pesos de ponderación tanto a los sub-criterios y como a los criterios que componen las problemáticas que limitan la ejecución del Turismo de Base Comunitaria en la comuna de Panguipulli. Se elaboró y aplicó una entrevista de percepción cerrada. De esta manera, la investigación general de este proyecto consideró la metodología de Acción Participante, la que implicó asistir a núcleos de conversación con investigadores y profesionales del Programa de Turismo de Base Comunitaria del Centro de Estudios Ambientales (CEAM) de Universidad Austral de Chile; participar en talleres de transferencia técnica del Nodo de Turismo de Base Comunitaria de la Red de Turismo Comunitario Meliko Felen; participar en seminarios de TBC realizados por el CEAM UACh; la Corporación de Fomento Productivo (CORFO); Bosque Modelo Panguipulli y la Municipalidad de Panguipulli; finalmente se realizaron visitas a terreno para aplicar la entrevista de percepción cerrada al panel de expertos.

La Entrevista de Percepción Cerrada se aplicó a un panel de expertos, cuya selección fue hecha según su nivel de conocimiento y experiencia en la gestión del TBC en el área de estudio. Se involucraron la visión de tres tipos de actores, que intervienen directamente en el fomento de este tipo de Turismo en la comuna de Panguipulli y en la Región de Los Ríos, para otorgar versatilidad y objetividad a las respuestas y al análisis multicriterio final.

a) Investigadores de Turismo de Base Comunitaria: Está compuesto por tres académicos/ investigadores de Turismo de Base comunitaria, los cuales han realizado investigaciones pioneras de TBC en distintos territorios de la Región de Los Ríos, en base a metodologías de Acción Participante. Estos expertos están vinculados al programa de Turismo de Base Comunitaria del Centro de Estudios Medio ambientales y al Instituto de Turismo de la Universidad Austral de Chile. Sr. Guillermo Pacheco, Coordinador del programa de Turismo de Base Comunitaria del Centro de Estudios Ambientales (CEAM) de la Universidad Austral de Chile, Sr. Christian Henríquez, Académico de Magister de Desarrollo a Escala Humana de la Universidad Austral de Chile y Sr. Edgardo Oyarzun, Académico del Instituto de Turismo de la Universidad Austral de Chile.

b) Comunidad Local: Está compuesto por tres empresarios y representantes de agrupaciones locales de Turismo de Base Comunitaria de la comuna de Panguipulli, que se han destacado por su participación y desarrollo del turismo comunal. Sra Nelda Trafipan; Empresaria turística de la localidad de Liquiñe y miembro de la Corporación de Turismo de Panguipulli, Srta Angélica Chincolef, Empresaria de Turismo de Base 
Comunitaria de la localidad de Coñaripe y premio Valor Turístico de la región de Los Ríos año 2015 y Sr. Mario Neihual, Egresado de Antropología, Presidente de la Agrupación de Guías de Liquiñe de la comuna de Panguipulli.

c) Gestores Públicos: está compuesto por tres profesionales que pertenecen a instituciones públicas y privadas relevantes en la toma de decisiones y gestión de la actividad turística de la comuna de Panguipulli y en la Región de Los Ríos. Sr. Sergio Toledo, Director la Oficina Municipal de Desarrollo Económico Local (OMDEL) de la Municipalidad de Panguipulli. Sr. Héctor Pichun, Profesional de Apoyo de la Corporación Bosque Modelo de la Corporación Nacional Forestal de Panguipulli y Sr. Pedro Burgos, Director Regional del Servicio Nacional de Turismo (SERNATUR) Región de Los Ríos.

\section{Tratamiento estadístico de los datos.}

El panel de expertos entregó varias respuestas, por lo cual los valores mínimos y distancias de impacto fueron calculados con el promedio de las respuestas entregadas por los distintos actores. Estos son los valores que determinaron el comportamiento de las variables y como las mismas influyen dentro de la evaluación de problemáticas de Turismo de Base Comunitaria en la comuna de Panguipulli.

De la misma forma a fin de evaluar el grado de acuerdo de las respuestas, correspondientes a los valores mínimos y distancias de impacto, se calcularon estadísticos de dispersión, en particular la varianza, desviación estándar y error estadístico de cada una de las variables. Dado que el análisis multicriterio se basa en la ponderación de las distintas variables que influyen dentro de un problema, es necesario estimar cuales son los pesos de importancia para cada uno de los criterios y sub criterios utilizados en la investigación. Se utilizó entonces, el Proceso Analítico Jerárquico (Saaty 1980), el que consiste en un procedimiento de comparación por pares de los criterios. Así, se establece una matriz de comparación, en la cual el número de filas y columnas está definido por el número de criterios a ponderar. En base a esta matriz se establecen los pesos y proporciona una medida cuantitativa de la consistencia (Saaty, 1980). Así, el panel de expertos según su experiencia y percepción, comparó los subcriterios y criterios definidos para esta investigación, a fin de obtener los pesos de cada uno de ellos.

Cabe señalar que, las respuestas fueron filtradas y promediadas en base al análisis de consistencia de manera de obtener el peso final para cada criterio y sub criterio que contempla esta investigación. Para asegurar la representatividad de los distintos tipos de actores, se forzó al menos la existencia de una respuesta consistente por cada tipo de actor, es decir en caso de que la totalidad de actores perteneciente a un grupo resultara inconsistente, la entrevista fue repetida. 
Finalmente, se realizaron comparaciones generales de los pesos asignados por cada uno de ellos a los criterios y sub criterios que limitan el desarrollo de TBC en la comuna de Panguipulli, a fin de investigar como varía la percepción de los distintos tipos de actores, respecto de la importancia relativa asignada para cada una de las preguntas de comparación.

\section{Resultados.}

Al calcular la desviación estándar de los valores minimos promedios, que mide el grado de influencia de la problemática para cada uno de los criterios y sbcriterios, se desprende que el subcriterio de Atrativos Turisticos posee la mayor variabilidad en los datos recogidos, con 0.3. Mientras que el error estándar de la muestra para esta variable es de 0.1 , por lo tanto los intervalos de confianza del $95 \%$ de la muestra, distribuye las respuestas entre un 0.2 y 0.4 de percepcion de influencia de la problemática. En tanto que los grados de acuerdo de las respuestas correspondiente a esta problemática, es de 76.8\% de coeficiente variacion.

Los subcriterios con menor desviación estándar de valor mínimo promedio de influencia de la variable son Proyectos Hidroeléctricos y Especulación Inmobiliaria con un 0.1 de valor minimo promedio, un error estándar de un 0.06 y 0.05 respectivamente y grados de acuerdo de las respuesta establecido por el coeficiente de variación de $165 \%$ y $70.7 \%$. Mencionar que al existir un érror estandar bajo provoca que exista un intervalo de confianza del 95\% de la muestra, donde se distribuyen los datos reducido, el rango se obtiene sumando y restando el érror estandar multiplicado por dos a la desviación estandar de cada una de las problemáticas seleccionadas para este estudio.

El subcrierio con mayor desviación estandar de distancia mínima promedio de influencia de la problemática, es Proyectos Hidroelectricos con 97.35 km de variación, un índice de error estandar del $95 \%$ de la muestra de 34.4, reflejando un intervalo de confianza de distribución de las respuestas entre los 8.2 y 202.9 km., mientras que los grados de acuerdo de las respuestas para este subcriterio es de $92.2 \%$ de coeficiente variación.

El subcriterio con menor desviación estandar en la distancia minima promedio de influencia de la variable es Caminos, esta problemática tiene un comportamiento mixto, en consecuancia se debíó calcular la variabilidad para la distancia minima y máxima promedio, las que corresponden a 3.38 y $5.22 \mathrm{kms}$ respectivamente, error estandar de 1.1 kms y $1, .8 \mathrm{kms}$ y alto grado de acuerdo para la distancia minima promedio de $148.5 \% \mathrm{y}$ bajo grado de acuerdo para la distancia máxima de $52.2 \%$, medido mediante el coeficiente de variación. La discrepancia entre la variabilidad con los grados de acuerdo para la distancia máxima y minima promedio de Caminos, se debe al bajo tamaño de la muestra 
que involucra la investigación.

Figura 11. Análisis estadístico de las variables para la evaluación de los Sub criterios.

\begin{tabular}{|c|c|c|c|c|c|}
\hline Variable & & Promedio & Desviacion Estándar & Error Estandar & Coeficiente de variacion \\
\hline \multirow[t]{2}{*}{ Proyectos Hidroelectricos } & Valor Minimo \% & 0.1 & 0.1 & 0.06 & 165 \\
\hline & Distancia (km) & 105.55 & 97.35 & 34.4 & 92.2 \\
\hline \multirow[t]{2}{*}{ Turismo Masivo } & Valor Minimo \% & 0.3 & 0.2 & 0.09 & 76.4 \\
\hline & Distancia (km) & 20.88 & 14.81 & 5.2 & 70.9 \\
\hline \multirow[t]{2}{*}{ Especulacion Inmobiliaria } & Valor Minimo \% & 0.2 & 0.1 & 0.05 & 70.7 \\
\hline & Distancia (km) & 31.44 & 29.7 & 10.5 & 94.4 \\
\hline \multirow[t]{2}{*}{ Organizaciones Comunitarias } & Valor Minimo \% & 0.1 & 0.2 & $0 . \infty 8$ & 166.4 \\
\hline & Distancia (km) & 7.65 & 6.15 & 2.1 & 80.4 \\
\hline Propiedad Indigena & Valor Minimo \% & 0.6 & 0.2 & 0.1 & 46.7 \\
\hline \multirow[t]{4}{*}{ Caminos } & Valor Mínimo/cerca \% & 0.7 & 0.2 & 0.07 & 28.5 \\
\hline & Valor Minimo/lejos \% & 0.4 & 0.2 & 0.08 & 52.9 \\
\hline & Distancia/cerca $(\mathrm{km})$ & 2.27 & 3.38 & 1.1 & 148.5 \\
\hline & Distancia/lejos (km) & 10 & 5.22 & 1.8 & 52.2 \\
\hline \multirow[t]{2}{*}{ Atractivos Turisticos } & Valor Minimo \% & 0.3 & 0.3 & 0.1 & 76.8 \\
\hline & Distancia (km) & 12.25 & 13.76 & 4.8 & 112.2 \\
\hline Empresas Formalizadas & Valor Minimo \% & 0.4 & 0.2 & 0.08 & 57.5 \\
\hline
\end{tabular}

Para el análisis de los valores mínimos y distancias mínimas promedios de los criterios, se calculó el promedio aritmético de los subcriterios que componen los criterios, que determinó que el criterio de Gestión Comunitaria es el conjunto de problemáticas con mayor riesgo a la presencia de las mismas, para el desarrollo del Turismo de Base Comunitaria, dado que los valores mininos promedios de impacto de las variable es de un 0.35 y distancia mínima promedio de influencia de ésta, es de $7.6 \mathrm{~km}$. En tanto que el conjunto de criterios evaluado con menor riesgo a las problemáticas corresponde a los conflictos productivos dado que el valor mínimo promedio de influencia de la problemática, es de un 0.2 y tiene un radio de influencia de distancia mínima promedio de influencia de $52.62 \mathrm{~km}$, considerando el tipo de comportamiento lineal directamente proporcional o inversamente proporcional de cada subcriterio que componen la primer criterio, dependiendo del valor mínimo y de la distancia mínima que influencian a cada variable.

La desviación estándar, dato estadístico que refleja la variabilidad común de los datos con respecto a la media aritmética del valor mínimo promedio, determinó que el criterio de Conflictos Productivos el que contiene menor dispersión en sus datos con una desviación estándar promedio de 0,13 para el valor mínimo promedio, un error estándar de 0.06 y altos grados de grados de acuerdo en las respuestas, las que alcanzan un promedio de $106 \%$ de coeficiente de variación. Sin embargo no ocurre la misma situación con los tres datos estadísticos analizados para la distancia mínima promedio, medida que posee una desviación estándar de un 47,28 km, un error estándar $43.1 \mathrm{~km}$ y un coeficiente de variación de $85.3 \%$. Reflejando una alta dispersión e intervalo de distribución de los datos 
pero con altos grados de acuerdo en las respuestas, la discrepancia entre la desviación estándar y el coeficiente de variación se debe al reducido tamaño de la muestra.

Mientras que el criterio de Infraestructura Turística contiene la mayor desviación estándar promedio de 0,25 para el valor mínimo promedio, un error estándar de 0.9 y coeficiente de variación promedio de $67.1 \%$ y para la distancia mínima promedio posee una desviación estándar de un $13.76 \mathrm{~km}$, un error estándar $4.8 \mathrm{~km}$ y un coeficiente de variación de $112.2 \%$.

Los pesos ponderados más altos en grado de importancia de limitaciones actuales que afectan el desarrollo de TBC en el área de estudio, fueron asignados para los subcriterios de proyectos hidroeléctricos y ausencia de organizaciones comunitarias con un 0.7 ; la lejanía a caminos y ausencia de atractivos turísticos fueron evaluados con un 0.3 . La no pertenecía a terrenos indígenas tiene un peso de importancia de 0.2 ; las zonas de especulación inmobiliaria de 0.1 y por último en categoría de importancia se consideró a las zonas de Turismo Masivo con una evaluación de un 0.09.

Con respecto a la evaluación de los criterios se consideró a los Conflictos Productivos un aspecto altamente problemático para el TBC asignándole un valor de un 0.5 ; el segundo aspecto determinó a la gestión comunitaria con un valor de 0.3 y por último se evaluó a la falta de infraestructura turística con un 0.09. (Véase la figura 12).

En cuanto a la variabilidad de las respuestas, el Criterio de Infraestructura turística posee la menor desviación estándar de 0.02, mientras los criterios de Conflictos Productivos y Gestión Comunitaria poseen mayor variabilidad en las respuestas, ambos con 0.32 . Asimismo, el error estándar para el criterio de Infraestructura turística es de 0.01, en tanto que para los dos criterios restantes es de 0.34. Por último, los tres criterios evaluados mediante este estudio poseen alta coincidencia en las respuestas con respecto a los pesos de importancia asignados a cada uno de los estos, promediando un $100.6 \%$ de coeficiente de variación. 
Figura 12. Promedio y datos estadístico de los pesos ponderados de Sub criterios y Criterios de Problemáticas de TBC.

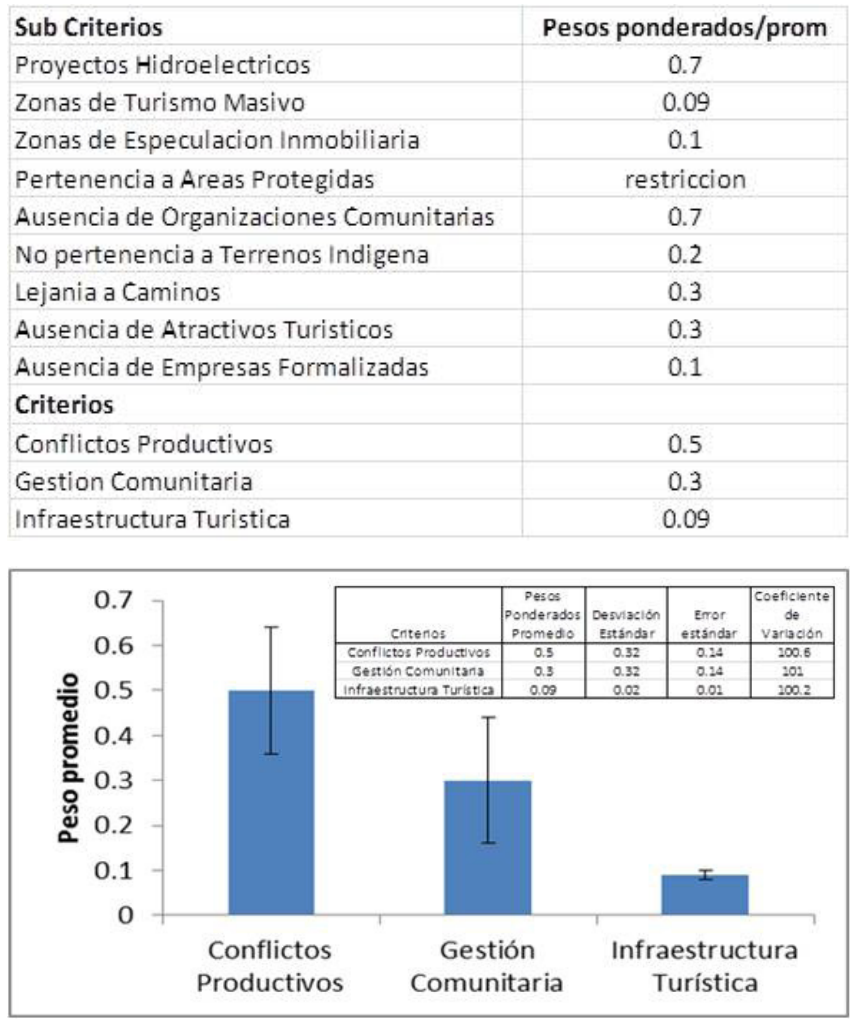

Para diferenciar las precepciones de las problemáticas que afectan al TBC entre tipos de actores que se involucraron en este estudio, se realizó un análisis estadístico diferenciado de los pesos promedios asignados a los criterios.

Para los Conflictos Productivos, los actores que le otorgan el mayor peso a la problemática son los Gestores Públicos con los Investigadores, ambos con un peso promedio asignado de 0.8 y 0.41 respectivamente, mientras que la comunidad local le asignó 0.18 . Si bien ésta variable tiene alto impacto en el alcance de la problemática, establecido por los km de distancia que ésta influencia, situación que es percibida por los actores externos al territorio donde se desarrolla TBC, es decir los Gestores Públicos y los Investigadores, quienes poseen mayor información de las potencialidades turísticas que existen en la comuna desde el punto de vista técnico, visión supra del territorio y el conocimiento de experiencias externas tanto nacionales como internacionales de ejecución de TBC. 
La desviación estándar de los Investigadores y Gestores Públicos es de 0.31 y 0.01 respectivamente, resultados que reflejan una baja variabilidad en las evaluaciones realizadas al igual un margen de error estándar pequeño, mientras que los grados de acuerdo de las respuestas son altos en los investigadores pero muy bajos en los gestores públicos, con un coeficiente de variación de $77.9 \%$ y $1.7 \%$ para cada uno. La discrepancia entre la baja desviación estándar y bajos grados de acuerdo de los datos correspondiente a los gestores públicos, se debe al bajo tamaño de la muestra que contempló este tipo de actor y inconsistencia reflejada por una las respuestas, lo que debilita el análisis estadístico.

La comunidad local evalúo con mayor peso de importancia a la problemática Gestión Comunitaria, asignándole un peso ponderado de 0.73 , mientras que los investigadores y los gestores públicos le asignaron un peso ponderado de 0.25 y 0.09 , ponderando un peso promedio de 0.35 . Mencionar que el peso ponderado asignado a este criterio por la comunidad local, está sustentado en la experiencia de las iniciativas del TBC, que se encuentran en desarrollo en el área, donde la no existencia de organizaciones comunitarias es contradictorio para la implementación asertiva de este tipo de turismo, mientras que la ausencia de terrenos indígenas si bien no es una limitante absoluta para su práctica, se requiere la propiedad de esta variable para tener dominio sobre las iniciativas que se impulsen como también conservar la existencia de la cultura Mapuche, que es un elemento complementario, diferenciador y que fundamenta la práctica del TBC. En tanto que las presencia de áreas protegidas es una varaible que limita la ejecucón de este tipo de turismo en las zonas declaradas como tales como el buffer aledaño debido a las regulaciones actuales que regulariza la administración y ocupación de éstas áreas destinadas a la protección y conservación de especies endémicas que existen en estas áreas, como también el método de concesiones para él la administración de actividades recreativa en estas áreas, las cuales son designadas mediante licitaciones públicas que involucran inversiones de capital inicial importante. La desviación estándar de la comunidad local es de 0.33 , reflejando una baja variabilidad en los datos y altos grados de acuerdos, medido mediante el coeficiente de variación que es de $130.8 \%$.

El Criterio de Infraestructura turística fue evaluado de forma similar por los tres tipos de actores, es decir asignado un peso ponderado de los investigadores de 0.09 , comunidad local de 0.08 y gestores públicos de 0.08 , tomado un peso ponderado promedio de 0.08 , con desviación estándar baja de 0.03 y 0.01 correspondiente a los investigadores y gestores públicos y ambos actores con bajo coeficiente de variación de $38.4 \%$ y $15.7 \%$ respectivamente. El tamaño de la muestra influencia la diferencia que se observa entre la variabilidad y los grados de acuerdos de las respuestas. Agregar que si bien el peso ponderado promedio asignado por los tres actores a este criterio es bajo, los subcriterios que lo componen son importantes para la práctica del TBC, puesto que los atractivos 
turísticos logran capturar la atención de la demanda, las empresas formalizadas son necesarias para crear y vender un producto turístico bajo la satisfacción de las necesidades que así exijan los turistas, bajo normas higiénicas administrativas que correspondan según los tipos de iniciativas que se encuentren habilitadas y la variable de caminos permite el traslado de la demanda turística a las zonas donde se realice TBC, en la comuna de Panguipulli.

Figura 13. Análisis estadístico de los pesos ponderados promedios, según tipo de actor.

\begin{tabular}{|c|c|c|c|c|}
\hline \multicolumn{5}{|c|}{ Criterio Conflictos Productivos } \\
\hline Actores/Criterios & Peso Promedio & Desviación Estándar & Error Estándar & Coeficiente de Variación \\
\hline Investigadores de TBC & 0.41 & 0.31 & 0.18 & 77.9 \\
\hline Comunidad Local & 0.18 & $\mathrm{~N} / \mathrm{A}$ & $N / A$ & $N / A$ \\
\hline Gestores Públicos & 0.8 & 0.01 & 0.01 & 17 \\
\hline Peso Criterio & 0.46 & & & \\
\hline \multicolumn{5}{|c|}{ Criterio Gestion Comunitaria } \\
\hline Actores/Criterios & Peso Ponderado & Desviacion Estandar & Error Estándar & Coeficiente de Variación \\
\hline Investigadores de TBC & 0.25 & 0.32 & 0.18 & 130.8 \\
\hline Comunidad Local & 0.73 & $\mathrm{~N} / \mathrm{A}$ & $\mathrm{N} / \mathrm{A}$ & $N / A$ \\
\hline Gestores Públicos & 0.09 & 0 & 0 & 0 \\
\hline Peso Criterio & 0.35 & & & \\
\hline \multicolumn{5}{|c|}{ Criterio Infraestructura Túristica } \\
\hline Actores/Criterios & Peso Ponderado & Desviación Estándar & Error Estándar & Coeficiente de Variación \\
\hline Investigadores de TBC & 0.09 & 0.03 & 0.02 & 38.49001795 \\
\hline Comunidad Local & 0.08 & $\mathrm{~N} / \mathrm{A}$ & $N / A$ & $N / A$ \\
\hline Gestores Públicos & 0.09 & 0.01 & 0.01 & 15.71349403 \\
\hline Peso Criterio & 0.08 & & & \\
\hline
\end{tabular}

En la figura 14 se exhiben tres mapas, que reflejan los criterios o problemáticas que afectan el TBC en Panguipulli, cuyo peso ponderado de la problemática refleja el valor del peso promedio asignado por los actores a cada uno de ellos. Para los pesos promedios altos, es decir cercanos a los sectores con una evaluación de riesgo cercana a 1 , se expresan mediante las grillas de color rojo mientras que los pesos promedios bajos con una evaluación cercanos a 0 , corresponden a las grilla de color azul.

En la comuna de Pangupulli, se localiza la central hidroeléctrica de paso Pullinque, actualmente pertenece a Empresas de Energia de.Pangupulli, filial de ENEL, se construyó entre 1958 y 1962, con potencia para la generación eléctrica de 229 GWh, esta obra extrae parte de la cuenca hidrográfica del rio huenahue, que se alimenta del Lago Calafquen y creando la laguna artificial de Pullinque, localizada en el sector de Pullinque, al norponiente de Panguipulli. 
Se evidencian tres proyectos de construcción de centrales hidroeléctricas, los que se incorporaron a este estudio como posibles amenazas para el desarrollo del TBC, los cuales se distribuyen como sigue: Central de pasada Neltume, extensión de la instalación de 20 ha, potencia de generación eléctrica de $1885 \mathrm{GWh}$ anuales, a localizar en el rio Fuy entre los sectores de Pirihueico y Neltume, proyecto hidroeléctrico Pellaifa, extensión de la instalación 19 ha, potencia de generación eléctrica de $108 \mathrm{MWh}$, a localizar en áreas cercanas al lago Pellaifa, extrayendo parte de las cuencas hidrográficas del rio Llancahue y Quilalelfu, proyecto hidroeléctrico Liquiñe, extensión a inundar de 18 ha, potencia de generación eléctrica de $20 \mathrm{MWg}$, a instalar en ubicada en la zona de Reyehueico, algunos kilómetros antes de la localidad de Liquiñe.

Es en torno a estos puntos que se crea una zona bufer de $105 \mathrm{~km}$. Desde donde se intensifican los sectores problemáticos para la instalación de iniciativas turísticas, lo mismo sucede en torno a los lagos, donde se practica turismo masivo y las áreas cercanas a las ciudades, que son indicadores para este estudio de zonas de especulación inmobiliaria, sin embargo, estas zonas no presentan altos riegos para esta actividad turística, esto se debe a los pesos ponderados promedios cuantificados son bajos, de 0.09 y 0.1 respectivamente.

La Figura 14 Exhibe tres mapas temáticos donde se reflejan explícitamente los criterios de Conflictos Productivos, Organización Comunitaria y Falta de Infraestructura Turística que limitan el desarrollo del TBC en la comuna de Panguipulli de la Región de Los Ríos, señalar que las zonas de color rojo pertenecen a las áreas territoriales que presentan mayores problemáticas cuyas grillas tienen un valor cercano a 1 y las zonas de color azul pertenecen a aquellas zonas que presentan menores problemáticas cuyas grillas tienen un valor cercano a 0 .

Agregar que la determinación de las zonas problemáticas en los mapas, se realizó en base a la evaluación jerárquica de pesos ponderados promedios determinada por los tipos de actores en conjunto con el procesamiento de las capas y datos geográficos que fueron seleccionadas para exhibir los criterios y subcriterios seleccionados como problemáticas que intervienen en el TBC, las que fueron ingresados y transformados en el Software Arc Gis, como también tratados y modelados en el Software Idrisi versión selva. 
Figura 14. Mapas de los criterios que afectan el desarrollo de Turismo de Base Comunitaria en la comuna de Panguipulli.

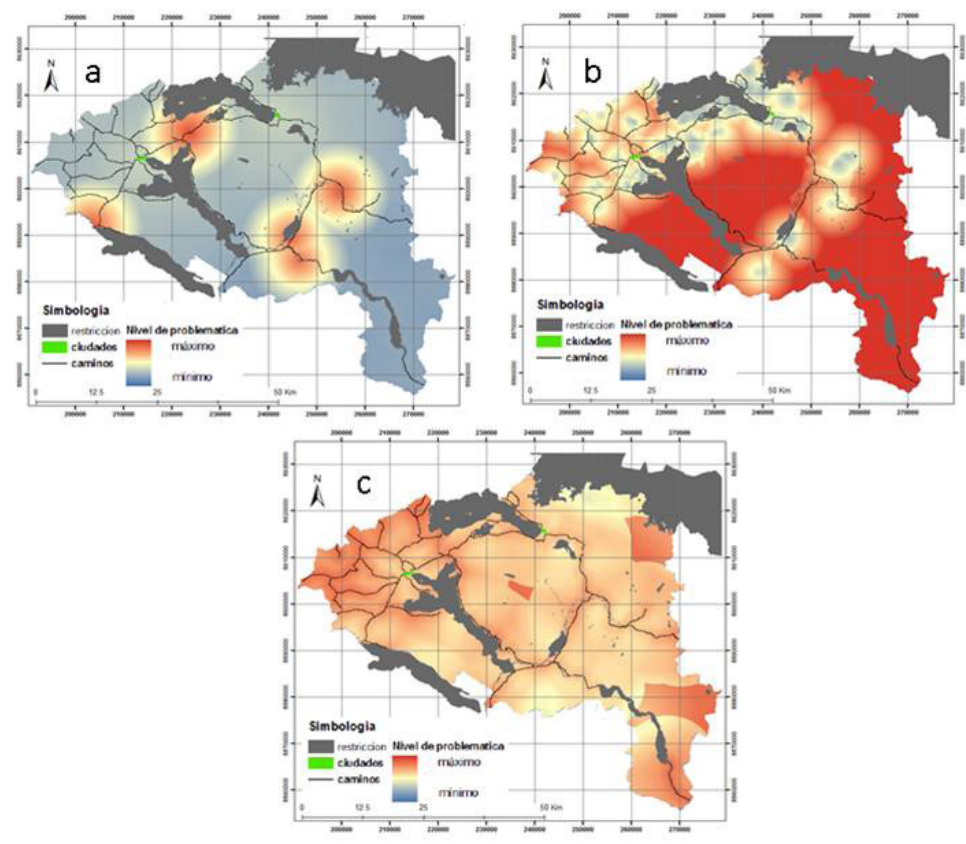

El mapa A de Conflictos Productivos, exhibe que en la comuna de Pangupulli las zonas de mayor riesgo para el desarrollo de TBC, se encuentran en torno a los terrenos cercanos a los 5 Proyectos Hidroeléctricos, estos son la central hidroeléctrica de paso Pullinque, que pertenece a Empresas de Energía de.Pangupulli, filial de ENEL, construida entre 1958 y 1962 con potencia para la generación eléctrica de $229 \mathrm{GWh}$, esta obra extrae parte de las cuenca hidrográfica del río Huenahue que se alimenta del Lago Calafquen y creó la laguna artificial de Pullinque, localizada en el sector del mismo nombre, al suroniente de la comuna de Panguipulli se encuentra la Central hidroeléctrica de paso San Pedro ubicada en el río San Pedro, a 15 km de Riñihue comuna de Los Lagos de la Región de Los Ríos. A su vez existen tres proyectos de construcción de centrales hidroeléctricas, la cuales se incorporaron a este estudio como posibles amenazas para el desarrollo del TBC, los cuales se distribuyen como sigue: central de pasada Neltume ${ }^{1}$, extensión de la instalación de 20 ha, potencia de generación eléctrica de 1885 GWh anuales, a localizar en el río Fuy entre los sectores de Pirihueico y Neltume, proyecto hidroeléctrico Pellaifa, extensión de

1 Este proyecto hidroeléctrico actualmente ha sido cancelado ya que la empresa no cuenta con los derechos de agua necesarios para la proyección de los volúmenes de agua proyectados para la central hidroelétrica. A esto se suman los movimientos de las comunidades, organizaciones mapuche y colaboradores que lograron encontrar argumentos y limitantes jurídicas que, finalmente, desencadernaron el fin del proyecto. 
la instalación 19 ha, potencia de generación eléctrica de $108 \mathrm{MWh}$, a localizar en áreas cercanas al lago Pellaifa, extrayendo parte de las cuencas hidrográficas del río Llancahue y Quilalelfu, proyecto hidroeléctrico Liquiñe, extensión a inundar de 18 ha, potencia de generación eléctrica de $20 \mathrm{MWg}$, a instalar en Reyehueico, algunos kilómetros antes de la localidad de Liquiñe, todas ubicadas en el sector poniente de la comuna.

Es en torno a estos puntos que se crea una zona buffer de $105 \mathrm{~km}$, radio en el que se intensifican los sectores problemáticos para la instalación de iniciativas turísticas puesto que este subcriterio fue evaluado con un peso ponderado promedio de 0.7 , lo mismo sucede en torno a los lagos donde se practica turismo masivo y a las ciudades donde los terrenos generan especulación inmobiliaria, los dos últimos subcriterios no presentan zonas de altos riegos para esta actividad turística ya que los pesos ponderados promedios asignados son de 0.09 y 0.1 respectivamente y alcanzan un radio 20.8 y $31.4 \mathrm{~km}$ de influencia respectivamente.

El mapa B de Gestión Comunitaria, exhibe que en la comuna de Panguipulli las zonas de mayor riesgo para el desarrollo del TBC, se encuentran en torno a los terrenos cercanos a la Ausencia de Organizaciones Comunitarias, la que fue evaluada con un peso ponderado promedio de 0.7 por los Tipos de Actores y tiene un radio de influencia de 7.65. Situación similar muestra la Ausencia de Terrenos Indígenas que fueron evaluados con un peso ponderado promedio de 0.6 y con un radio de influencia igual a 0 . Por último es preciso mencionar que el subcriterio de Presencia de Áreas Protegidas es un subcriterio limitante absoluto para la realización de actividades de Turismo de Base Comunitaria debido a las dificultades legislativas que no permiten a la Comunidad Local hacer uso de estas áreas. Por tanto debido a la baja existencia de estos dos los primeros aspectos y la presencia en la zona de dos áreas protegidas es el mapa de Organizaciones Comunitaria exhibe la mayor parte de la comuna con presencia de problemáticas para el desarrollo del TBC y solo exhibe zonas aptas para ejecutar iniciativas de esta índole en el área norponiente y centro de la comuna de Panguipulli, es decir en torno a donde se encuentran georreferenciadas las Organizaciones Comunitarias y los Terrenos Indígenas.

El mapa C de Falta de Infraestructura Turística, exhibe que en la comuna de Panguipulli las zonas de mayor riesgo para el desarrollo del TBC, se encuentran en torno a los terrenos cercanos a la Ausencia de Caminos, la que fue evaluada con un peso ponderado promedio de 0.3 por los Tipos de Actores y que exhibe un zona buffer de influencia en torno a este subcriterio, de distancia mínima de $2.27 \mathrm{~km}$ y de distancia máxima de $10 \mathrm{~km}$. En tanto que los dos subcriterios restantes no presencia mayor influencia dentro de las problemáticas porque sus pesos ponderados promedio son bajos tomando los valores de 0.3 la variable de Presencia de Atractivos Turísticos con radio de influencia para el primero de 12.25 km y 0.1 la variable de Empresas Formalizadas, la que por ser de naturaleza factorial no 
presenta radio de influencia en distancia. Por tanto debido a la baja influencia en áreas de estas variables, este criterio no presenta terrenos con alta presencia de problemáticas.

Figura 16. Mapas de aptitud para el desarrollo de Turismo de Base Comunitaria en la comuna de Panguipulli, Región de Los Ríos.

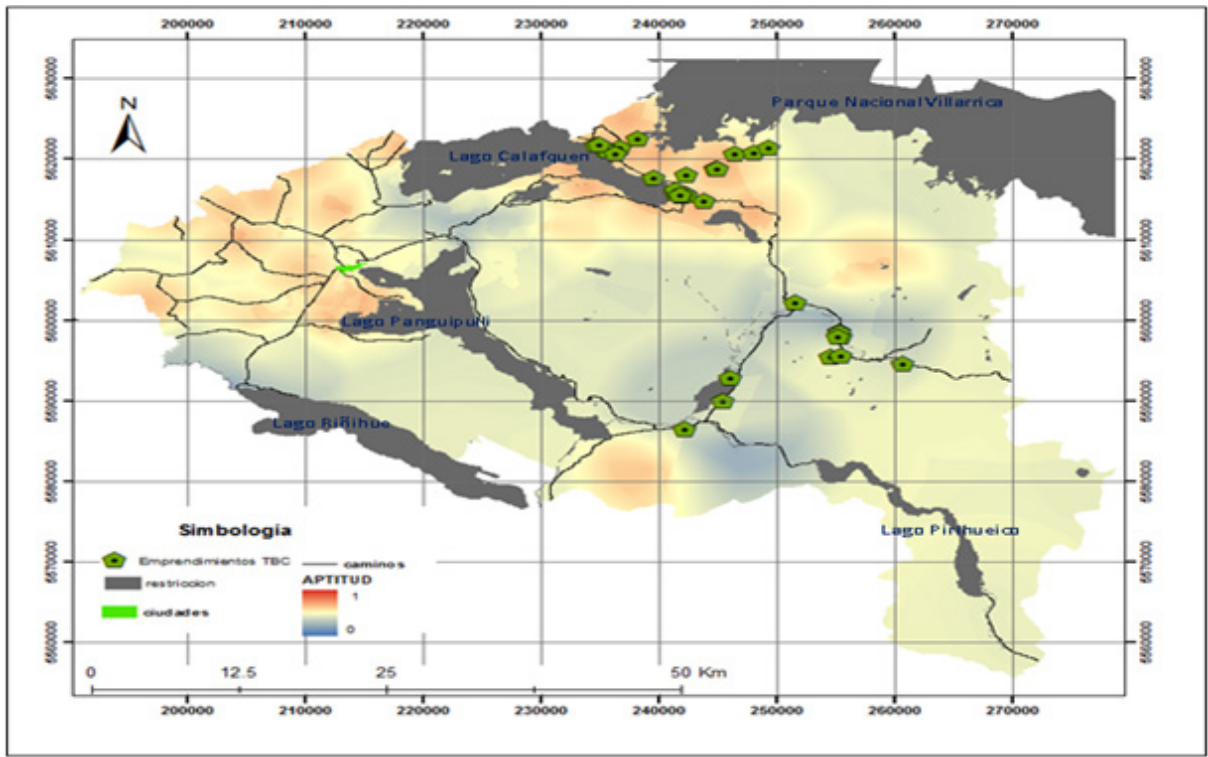

En cuanto a las zonas de aptitud para el desarrollo del Turismo de Base Comunitaria, este mapa se obtuvo integrando y tratando los datos estadisticos de los valores promedios minimos, las distancia minima de influencia y los pesos ponderados promedios de los subcriterios en conjunto con las capas y datos geográficos de tres criterios ya tratados en el software Idrisi versión selva y mejorado en su diseño en el software ARC Gis, donde se obtuvo que las zonas más aptas para el TBC en la comuna de Pnaguipulli, corresponden a las zonas de color rojo, cuyas grillas se acercan al valor de 1, las cuales se localizan en la zona norte intermedia, en la zona norponiente y las zona sur bajo el lago Panguipulli mientras que las zonas con menor aptitud para desarrollar TBC en la Comuna de Panguipulli, cuyas grillas se acercan a valor 0 , se localizan en las zona interrior media, en la zona este y zona sur poniente del area de estudio casi al colinde adminitrativo con la comuna de Los Lagos. Según lo anterior, los terrenos que presentan mayor extensión en 
la comuna de Panguipulli de la Región de Los Ríos corresponden a las areas que poseen aptitud media a alta para el desarrollo de Tursimo de Base Comunitaria. Datos geograficos que evidencian una oportunidad para fomentar el desarrollo de este tipo de turismo.

En cuanto a la ubicación de los actuales emprendimientos que se encuentran trabajando en Turismo de Base Comunitaria 14 de ellos se encuentran localizados en zonas con alta aptitud y 11 de ellos se encuentran localizados en zonas de baja aptitud para la ejecución del TBC, según los criterios y subcriterios que intervienen en la aptitud en el terreitorio donde se realizó la investigación.

\section{Conclusiones y discusión}

Aplicar técnicas de ordenamiento territorial a la planificación turística sirve para focalizar la toma de decisiones, sin embrago, el uso de estas técnicas necesita de base de datos geográficos, los cuales actualmente que son escasos ya que no han sido sistematizados por las instituciones gubernamentales como privadas que estab encargadas de fomentar y gestionar la actividad turística en la comuna de Panguipulli de la Región de Los Ríos.

Al finalizar el análisis territorial reflejado mediante los mapas, es posible afirmar que no existe la aptitud 0 para desarrollar Turismo de Base Comunitaria. Esto se debe a que las problemáticas evaluadas son contrarrestables por las mismas iniciativas y la gestión organizacional comunitaria de las Comunidades Locales.

Asimismo, las respuestas poseen bajos grados de acuerdo, lo que se debe al reducido tamaño de la muestra a la que se le aplicó la metodología, la diferencia en opiniones según los Tipos de Actor y al uso diferenciado de los recursos naturales y culturales. Esta misma situación se da para explicar la alta variabilidad de Los Atractivos Turístico, subcriterio que presenta parámetros entre un $76.8 \%$ para el valor mínimo y $112.2 \%$ para la distancia y $100.9 \%$ para el peso ponderado promedio.

Para estudios posteriores es recomendable diferenciar cada tipo de TBC según los recursos que lo sustenten. Así, se reduciría la variabilidad en las valoraciones por tipos de actores ya que se detectó una diferencia en la percepción entre los distintos tipos de actores, particularmente entre la Comunidad Local y los demás. La Infraestructura turística fue evaluada como el criterio menos importante en la aptitud de unterritorio(9\%), estosedebealomanejablequeesteaspectodentrodeunterritorioturístico. 
La mayor parte de los emprendimientos de TBC (22) están ubicados en zonas aptas. Sin embargo, existe un número importante de emprendimientos (11) ubicados en zonas con baja aptitud.

Por último el análisis espacial es una técnica aplicable al TBC debido a que otorga una visión sinóptica de las problemáticas que limitan el desarrollo de este tipo de turismo en la comuna de Panguipulli de la Región de Los Ríos y se cumple el objetivo de complementar la planificación y el ordenamiento territorial turístico, mediante el uso de estas herramientas.

\section{Bibliografía}

Brida, Pereira, Such Devesa y Zapata Aguirre, 2008. La contribución del Turismo al Crecimiento Económico, revista electrónica: Cuadernos del Turismo, volumen $\mathrm{N}^{\circ} 22$, página 35-46, recuperado en http://revistas.um.es/turismo/article/view/47931/45901.

Henríquez, C., Zechner, Talita y Sampaio, Carlos A. 2010. Turismo y sus interacciones en las transformaciones del espacio rural. Rev. Austral cienc. soc., no.18, p.21-31.

Henríquez, Christian.; Pilquiman, M.; Skewes, J.C.; Sampaio, C.A.C. 2011. Culturas originarias e turismo: una experiencia de turismo comunitario en el mundo Mapuche, Tralcao, Sur de Chile. Revista Brasileña de Ecoturismo, São Paulo, v.4, n.4, p. 498. 2012.

Pacheco, Guillermo; Castaing, Juan Carlos Edit. 2014. La Gestión de Destinos en la Región de Los Lagos: Una guía para el Turismo de Intereses Especiales. Universidad de los Lagos /CORFO. Ediciones Departamento de Gobierno y Empresa de la Universidad de Los Lagos, Puerto Montt, Chile. Abril de 2014.

Pacheco, Guillermo 2015. Turismo de Base Comunitaria y procesos de gobernanza en la comuna de Panguipulli: Un análisis comparativo con la experiencia brasileña. En IV Congreso de Cultura y Educación para la Integración de América Latina-"el Buen Vivir", en la Mesa denominada "Turismo, Territorio y Comunidades: Mirada intercultural para el desarrollo incluyente, sustentable y sustentado". Organizado por el Programa ATLAS y CentrodeEstudios deDesarrolloRegionalyLocal(CEDER)delaUniversidaddeLosLagos, Chile, junto con Red CASLA CEPIAL y la Fundación para la Superación de la Pobreza.

Pacheco, Guillermo 2015. Turismo Comunitario y Economía Solidaria: Una alternativa de desarrollo local para Panguipulli. En IV Congreso de Cultura y Educación para la Integración de América Latina - "el Buen Vivir", línea temática Trafkintu (Economía). Organizado por el Programa ATLAS y Centro de Estudios 
de Desarrollo Regional y Local (CEDER) de la Universidad de Los Lagos, Chile, junto con Red CASLA CEPIAL y la Fundación para la Superación de la Pobreza.

Pacheco Habert, G.; Henríquez Zúñiga, C. 2016. El turismo de base comunitaria y los procesos degobernanza en la comuna de panguipulli, sur de Chile. Gestión Turística, núm. 25, enero-junio, pp. 42-6 Universidad Austral de Chile, Valdivia, Chile

Coriolano, Luzia Neide ; Lima, Luiz Cruz (org.) 2003. Turismo comunitario y responsabilidad socio ambiental. Fortaleza: Edecue.

López-Marrero, Tania, González-Toro, Antonio, Heartsill-Scalley, Tamara y Hermansen-Báez, L. Annie. 2011. Evaluación Multicriterio y Sistemas de Información Geográfica para la planificación y la toma de decisiones acerca del uso de terrenos;

Ramírez, Mirta Liliana. 2004. El Método de jerarquías analíticas de Saaty en la ponderación de variables. Aplicación al nivel de mortalidad y morbilidad en la provincia del Chaco. 